\title{
PEGylated calix[4]arene as a carrier for a Bodipy-based photosensitizer
}

\author{
Yusuf Cakmak $^{\mathrm{a}}$, Tugrul Nalbantoglu ${ }^{\mathrm{b}}$, Tugce Durgut ${ }^{\mathrm{b}}$, Engin U. Akkaya ${ }^{\mathrm{a}, \mathrm{b}, *}$ \\ a UNAM-National Nanotechnology Research Center, Bilkent University, 06800 Ankara, Turkey \\ ${ }^{\mathrm{b}}$ Department of Chemistry, Bilkent University, 06800 Ankara, Turkey
}

\section{A R T I C L E I N F O}

\section{Article history:}

Received 19 July 2013

Revised 5 November 2013

Accepted 20 November 2013

Available online 28 November 2013

\section{Keywords:}

Bodipy

Photosensitizers

Singlet oxygen

Calixarenes

PDT

\begin{abstract}
A B S T R A C T
Heavy atom substituted Bodipy compounds, unlike the parent chromophore, undergo rapid intersystem crossing to generate singlet oxygen, which is the primary cytotoxic agent exploited in PDT. In this work, we show that an organic soluble calix[4]arene can be functionalized by Knoevenagel reaction and then converted into an amphiphilic photosensitizer in a few steps. In addition to generating a potentially useful photosensitizer, the sequence of reactions is the first use of a Bodipy dye as a chromophoric/fluorogenic label without the typical reactive functional groups.
\end{abstract}

(C) 2013 Elsevier Ltd. All rights reserved.
Photodynamic therapy (PDT) is a non-invasive or moderately invasive alternative to more traditional therapeutic methodologies such as surgery, chemotherapy, and radiation therapy. ${ }^{1}$ Photodynamic therapy has a built in selectivity, as the cytotoxic action is contingent upon the presence of the three components at the same spatiotemporal coordinates, namely, light, sensitizer, and dissolved oxygen. Consequently, by controlling the region of irradiation, some regioselectivity can be achieved.

Recent years have witnessed a growing interest in the outof-the-box proposals for generating and controlling the photodynamic action. ${ }^{2}$ At the same time, novel chromophore families have been introduced as potential sensitizers. ${ }^{3}$ Bodipy dyes have emerged as a promising class, ${ }^{4}$ in part, due to our contributions highlighting the chemistry ${ }^{5}$ and singlet oxygen generation capacity ${ }^{6}$ of these compounds. Bodipy dyes were previously recognized as chemically and photochemically stable chromophores, and part of this stability was ascribed to the inaccessibility of the triplet manifold, thus reducing the chances of potential degradative interactions with ambient oxygen. However, Bodipy dyes can be transformed into efficient photosensitizers by the incorporation of heavy atoms ${ }^{4 \mathrm{~d}}$ or by increasing the degeneracy of the excited state frontier orbitals. ${ }^{6}$

Another matter of concern is the wavelength of irradiation. Current PDT practice makes use of porphyrins or closely related derivatives. ${ }^{1,7}$ These dyes have relatively weak absorptions in the

\footnotetext{
* Corresponding author.

E-mail address: eua@fen.bilkent.edu.tr (E.U. Akkaya).
}

red part of the visible spectrum where mammalian tissues are most transparent. ${ }^{4 \mathrm{~b}}$ Therefore, the ever existing drive to obtain dyes with strong absorptions in the red and near IR region of the spectrum is understandable.

Bodipy dyes are likely to evolve into satisfactory alternatives to the traditional core of sensitizers. The absorption bands of the Bodipy dyes are highly tunable. In particular, in those with styryl substitution, the absorption peak can be located anywhere from 500 to $850 \mathrm{~nm}^{4 \mathrm{~b}, 5 \mathrm{c}, 8}$

With these considerations, we designed compound $\mathbf{5}$ as the target molecule (Fig. 1). The synthesis started with a partially tert-butylated calixarene derivative 1. This compound can be obtained in three steps from commercially available compounds starting from the most common entry point to the calixarene chemistry, tetrakis-tert-butylcalix[4]arene, ${ }^{9}$ following literature precedence $^{10}$ (detailed reaction steps can be found in the Supplementary data). Refluxing compound 1 with 1-bromodecane in acetonitrile in the presence of anhydrous potassium carbonate yielded the tetradecylated product in frozen cone conformation. Subsequent formylation in TFA with hexamethylenetetramine (HMTA) at an elevated temperature yielded the key intermediate $\mathbf{2}$ as the major product (99\% yield).

Intermediate $\mathbf{3}$ was reported in earlier work $^{5 a}$ and under Knoevenagel condensation conditions reacted with 2 to form a monocondensation product. This reaction is an interesting demonstration of the versatility of the Bodipy chromophore. Thus, two Bodipy dyes were successfully attached to the upper rim of the calix[4]arene. A second condensation reaction, this time with 


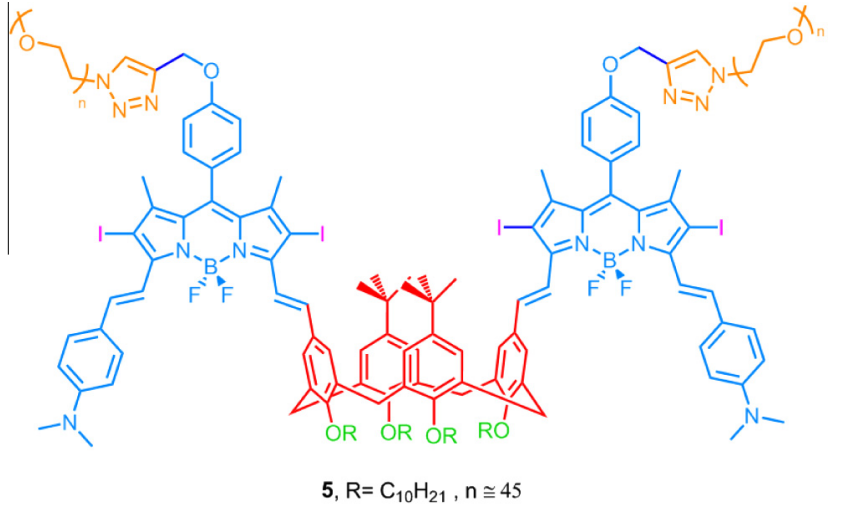

Figure 1. The structure of the targeted calix-Bodipy photosensitizer, $\mathbf{5}$.

4-(dimethyamino)benzaldehyde yielded compound $\mathbf{4}$ in which the extended conjugation pushes the main absorption band corresponding to the $S_{0}-S_{1}$ transition from red to near infrared wavelengths (725 nm in PBS solution, Fig. S3). In the final step, an azide-alkyne Huisgen cycloaddition reaction was carried out under standard conditions with methoxypolyethyleneglycol azide $(\mathrm{MW}=2000 \mathrm{~g} / \mathrm{mol}) .^{5 \mathrm{a}}$ The reaction proceeded smoothly to yield a water soluble, yet amphiphilic derivative $\mathbf{5}$ which was expected to be a potent photosensitizer by design (Scheme 1). Thus, two Bodipy units were tethered to the calix[4]arene and this reaction extends the conjugation such that the absorption of the Bodipy dye is within the so-called 'therapeutic window'. The Bodipy core was previously assembled on the calixarene lower rim, ${ }^{11}$ but this is the first time a fully formed Bodipy unit is conjugated to a calixarene through a Knoevenagel reaction.

The electronic absorption spectrum of the sensitizer shows a strong peak at $725 \mathrm{~nm}$ in aqueous solutions, with an extinction coefficient of $130,000 \mathrm{M}^{-1} \mathrm{~cm}^{-1}$. Thus, the compound is clearly a strong near infrared absorber.

The singlet oxygen generation capacity of the target compound was studied in both organic and aqueous solutions. For assessing activity in organic solutions, 1,3-diphenyl-iso-benzofuran (DPBF) was used as a trap (Fig. 2, top). In a typical experiment, $46 \mathrm{nM}$ of
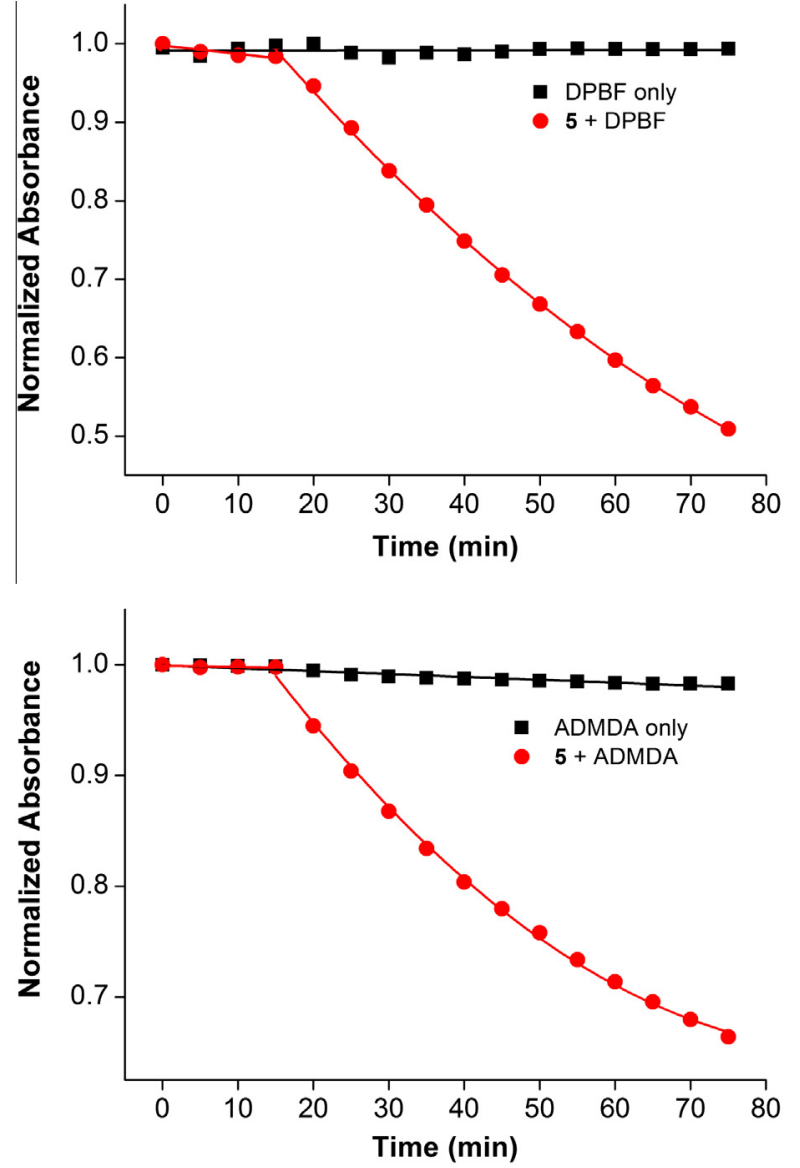

Figure 2. Time course of the decomposition of trap molecules upon irradiation with a $725 \mathrm{~nm}$ LED array in the absence (black squares) and presence (red circles) of $\mathbf{5}$; in IPA using an organic soluble trap molecule, 1,3-diphenyl-iso-benzofuran (DPBF) with (red circles) and without (black squares) $46 \mathrm{nM}$ sensitizer 5 (top); in PBS buffer (pH 7.4) using the water soluble trap molecule, 2,2'-[anthracene-9,10-diylbis(methylene)]-dimalonic acid (ADMDA) with (red circles) and without (black squares) $2.3 \mu \mathrm{M}$ sensitizer $\mathbf{5}$ (bottom). For the first $15 \mathrm{~min}$ the light source was turned off and then turned on.

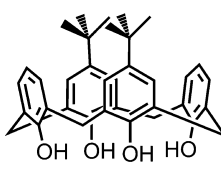

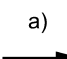

b)

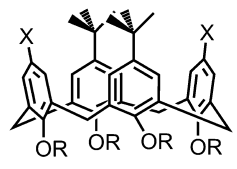

2, $\mathrm{X}=-\mathrm{CHO}, \mathrm{R}=-\mathrm{C}_{10} \mathrm{H}_{21}$

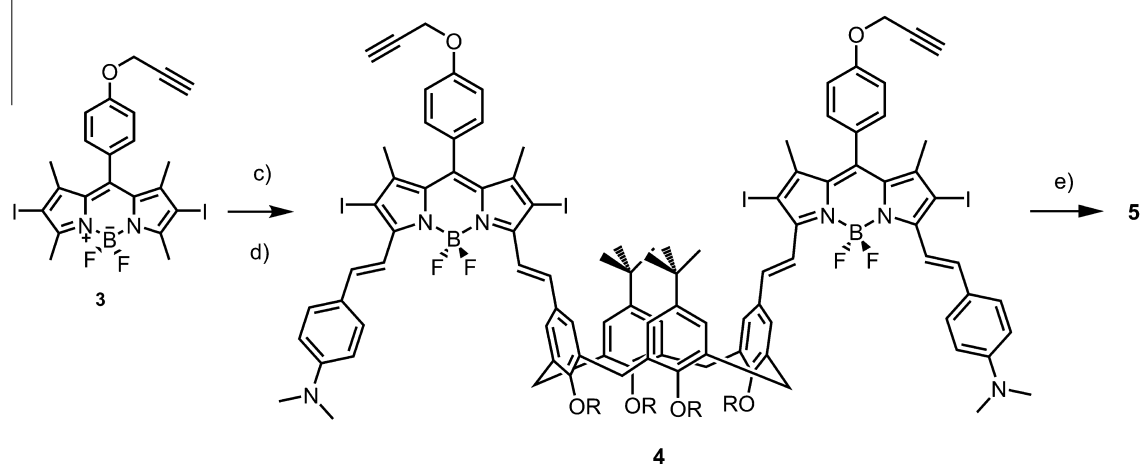

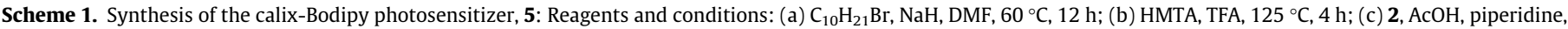
$\mathrm{C}_{6} \mathrm{H}_{6}$, reflux (Dean-Stark); (d) 4-(dimethylamino)benzaldehyde, AcOH, piperidine, $\mathrm{C}_{6} \mathrm{H}_{6}$, reflux (Dean-Stark); (e) PEG-N 3 (MW = 2000), CuI, DMF, $60{ }^{\circ} \mathrm{C}$, overnight. 


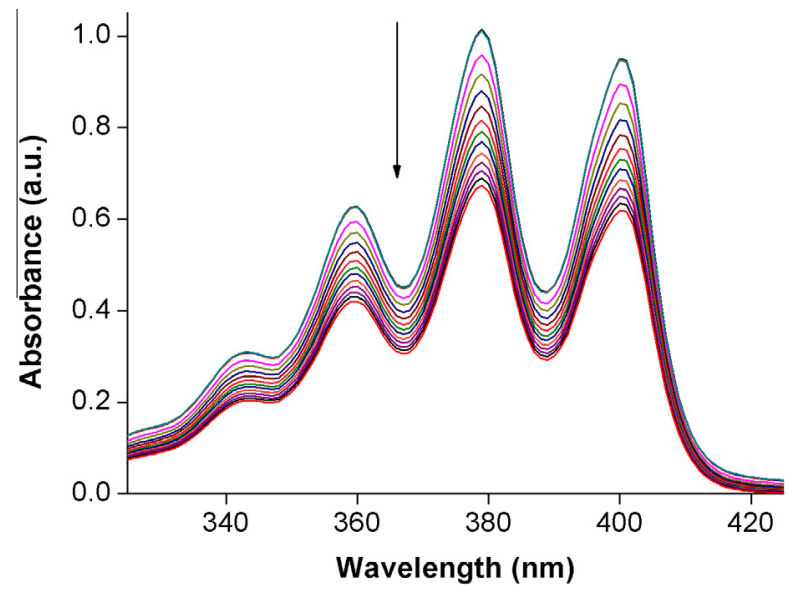

Figure 3. The change in the absorption spectrum as singlet oxygen is produced by sensitization in aqueous solution. ADMDA in the presence of $5(2.3 \mu \mathrm{M})$ in PBS solution ( $\mathrm{pH} 7.4$ ) was kept in the dark (15 min, no change, overlapping traces) and under near IR irradiation (at $725 \mathrm{~nm}$ for $60 \mathrm{~min}$ ).

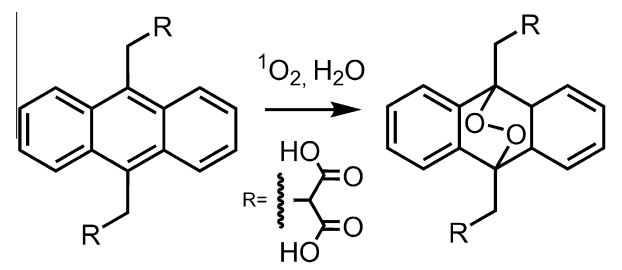

Figure 4. The structure and singlet oxygen reaction of the water-soluble ${ }^{1} \mathrm{O}_{2}$ scavenger molecule 2,2'-[anthracene-9,10-diylbis(methylene)]dimalonic acid (ADMDA). Absorbance due to the anthracene core diminishes as the reaction progresses.

the sensitizer $\mathbf{5}$ in isopropyl alcohol with a trap concentration of $10 \mu \mathrm{M}$ was subjected to irradiation from a $725 \mathrm{~nm}$ LED array. As expected, without the sensitizer, the absorption band due to DPBF did not change over time on near IR irradiation (black line). However, in the presence of the photosensitizer $\mathbf{5}$, the degradation started immediately once the LED array had been turned on (red line). In addition, a control experiment without light and with sensitizer was performed in the first $15 \mathrm{~min}$ of the experiment; no decrease in the absorbance of the trap molecule was observed, thereby eliminating any possibility of a dark reaction having occurred. The intensity of the light is in fact quite weak, typically less than $1 \mathrm{~mW} / \mathrm{cm}^{2}$. The activity in the aqueous solutions was also determined (Fig. 2, bottom, and Fig. 3), this time using a water soluble singlet oxygen trap, 2,2'-[anthracene-9,10-diylbis(methylene)]dimalonic acid (see Fig. 4 for structure and reaction with ${ }^{1} \mathrm{O}_{2}$ ), which was synthesized following a literature procedure. ${ }^{12}$ The photosensitization was then studied in an aqueous solution comprising PBS buffer (pH 7.4) and ethanol (90/10).

The trap $(1 \mu \mathrm{M})$ was irradiated in the presence and absence of the photosensitizer 5. Again, the trap molecule reacted only in the presence of the sensitizer $\mathbf{5}(2.3 \mu \mathrm{M})$. In this case too, control experiments showed that singlet oxygen generation activity only proceeded in the presence of the sensitizer and light.

In conclusion, we were able to functionalize calix[4]arene with two Bodipy chromophores with strong intersystem crossing tendency due to the presence of heavy iodine atoms attached to the Bodipy core. The long chain alkyl substituents on the calixarene lower rim provide some hydrophobic character, while the two PEG groups aid water solubility. The result is an amphiphilic photosensitizer. Considering the fact that most successful PDT photosensitizers are amphiphilic in nature, this is quite relevant. The use of styryl substitution ensures long wavelength (near IR) absorption. This extension of conjugation in $\mathbf{5}$ is another clear demonstration of the versatility of Bodipy chemistry.

We are confident that calixarenes functionalized in this manner will find applications as potential platforms for singlet oxygen carriers and delivery agents.

\section{Acknowledgment}

The authors gratefully acknowledge support from TUBITAK in the form of a Grant (110T076).

\section{Supplementary data}

Supplementary data (experimental procedures and analytical data for all the new compounds) associated with this article can be found, in the online version, at http://dx.doi.org/10.1016/ j.tetlet.2013.11.083.

\section{References and notes}

1. (a) Bonnett, R. Chem. Soc. Rev. 1995, 24, 19; (b) Dolmans, D. E. J. G.; Fukumura, D.; Jain, R. K. Nat. Rev. Cancer 2003, 3, 380; (c) Detty, M. R.; Gibson, S. L.; Wagner, S. J. J. Med. Chem. 2004, 47, 3897.

2. (a) Ozlem, S.; Akkaya, E. U. J. Am. Chem. Soc. 2009, 131, 48; (b) Erbas-Cakmak, S.; Bozdemir, O. A. Cakmak, Y.; Akkaya, E. U. Chem. Sci. 2013, 4, 858.

3. (a) Adarsh, N.; Shanmugasundaram, M.; Avirah, R. R.; Ramaiah, D. Chem. Eur. J. 2012, 18, 12655; (b) Oguz, U.; Akkaya, E. U. Tetrahedron Lett. 1997, 38, 4509.

4. (a) Awuah, S. G.; You, Y. RSC Adv. 2012, 2, 11169; (b) Kamkaew, A.; Lim, S. H.; Lee, H. B.; Kiew, L. V.; Chung, L. Y.; Burgess, K. Chem. Soc. Rev. 2013, 42, 77; (c) Awuah, S. G.; Polreis, J.; Biradar, V.; You, Y. Org. Lett. 2011, 13, 3884; (d) Adarsh, N.; Avirah, R. R.; Ramaiah, D. Org. Lett. 2010, 12, 5720; (e) He, H.; Lo, P. C.; Yeung, S. L.; Fong, W. P.; Ng, D. K. P. J. Med. Chem. 2011, 54, 3097; (f) Bozdemir, O. A.; Erbas-Cakmak, S.; Ekiz, O. O.; Dana, A.; Akkaya, E. U. Angew. Chem., Int. Ed. 2011, 50, 10907.

5. (a) Erbas, S.; Gorgulu, A.; Kocakusakogullari, M.; Akkaya, E. U. Chem. Commun. 2009, 4956; (b) Dost, Z.; Atilgan, S.; Akkaya, E. U. Tetrahedron 2006, 62, 8484; (c) Atilgan, S.; Ekmekci, Z.; Dogan, A. L.; Guc, D.; Akkaya, E. U. Chem. Commun. 2006, 4398; (d) Atilgan, S.; Ozdemir, T.; Akkaya, E. U. Org. Lett. 2010, 62, 4792

6. (a) Cakmak, Y.; Kolemen, S.; Duman, S.; Dede, Y.; Dolen, Y.; Kilic, B.; Kostereli, Z.; Yildirim, L. T.; Dogan, A. L.; Guc, D.; Akkaya, E. U. Angew. Chem., Int. Ed. 2011, 50, 11937; (b) Duman, S.; Cakmak, Y.; Kolemen, S.; Akkaya, E. U.; Dede, Y. J. Org. Chem. 2012, 77, 4516 .

7. Ethirajan, M.; Chen, Y. H.; Joshi, P.; Pandey, R. K. Chem. Soc. Rev. 2011, 40, 340.

8. Buyukcakir, O.; Bozdemir, O. A.; Kolemen, S.; Erbas, S.; Akkaya, E. U. Org. Lett. 2009, 11, 4644.

9. (a) Kim, H. J.; Lee, M. H.; Mutihac, L.; Vicens, J.; Kim, J. S. Chem. Soc. Rev. 2012 41, 1173; (b) Kim, J. S.; Lee, S. Y.; Yoon, J.; Vicens, J. Chem. Commun. 2009, 4791.

10. Dalbavie, J. O.; Regnouf-De-Vains, J. B.; Lamartine, R.; Lecocq, S.; Perrin, M. Eur. J. Inorg. Chem. 2000, 10, 683.

11. Baki, C. N.; Akkaya, E. U. J. Org. Chem. 2001, 66, 1512.

12. Martinez, G. R.; Garcia, F.; Catalani, L. H.; Cadet, J.; Oliveira, M. C. B.; Ronsein, G. E.; Miyarnoto, S.; Medeiros, M. H. G.; Di Mascio, P. Tetrahedron 2006, 62, 10762. 